(C) 2008 The Author

Journal compilation (C) 2008 Metaphilosophy LLC and Blackwell Publishing Ltd

Published by Blackwell Publishing Ltd, 9600 Garsington Road, Oxford OX4 2DQ, UK, and

350 Main Street, Malden, MA 02148, USA

METAPHILOSOPHY

Vol. 39, No. 1, January 2008

0026-1068

\title{
KOOKY OBJECTS REVISITED: ARISTOTLE'S ONTOLOGY
}

\author{
S. MARC COHEN
}

\begin{abstract}
This is an investigation of Aristotle's conception of accidental compounds (or "kooky objects," as Gareth Matthews has called them)—entities such as the pale man and the musical man. I begin with Matthews's pioneering work into kooky objects, and argue that they are not so far removed from our ordinary thinking as is commonly supposed. I go on to assess their utility in solving some familiar puzzles involving substitutivity in epistemic contexts, and compare the kooky object approach to more modern approaches involving the notion of referential opacity. I conclude by proposing that Aristotle provides an implicit role for kooky objects in such metaphysical contexts as the Categories and Metaphysics.
\end{abstract}

Keywords: accident, Aristotle, ontology, sameness, substitution.

In the course of my forty-year friendship and collaboration with Gary Matthews, he has taught me many things, more than I have space to enumerate here. So I won't try to enumerate them. Instead, I am going to focus on just one of those things - the idea that it is worth taking seriously a certain aspect of Aristotle's ontology that seems at least quaint, if not weird, to our contemporary ears. Its quaintness, or weirdness, consists in the fact that it is a finer-grained ontology than we are accustomed to - it distinguishes between entities that we tend not to distinguish, and hence gives ontological status to entities that philosophers nowadays are not entirely comfortable with.

Gary is not alone, of course, in his interest in this aspect of Aristotle's thought. Other scholars have given it different labels: Frank Lewis talks about Aristotle's "accidental compound theory" (Lewis 1982, 29 n. 11), and Nicholas White writes of Aristotle's doctrine of "modal individuation" (White 1986, 480). But the catchiest label for this view is Gary's he calls it Aristotle's theory of kooky objects (Matthews 1982 and 1992) — and the label seems to have stuck. So that is how I'll refer to it here. I am going to talk about kooky objects: what they are, where to find them in Aristotle's texts, and what roles they play in his metaphysics and epistemology. 


\section{I}

Kooky objects make their most obvious appearance in Aristotle's discussion of change in Phys. I.7, where he is discussing the case in which an unmusical man becomes musical. In such a case, he says, the man survives but the unmusical does not. It might seem that it is only the attribute of unmusicality, or perhaps the man's own peculiar bit of unmusicality, that Aristotle is supposing to perish when the man becomes musical, but he quickly dispels that impression: "The man survives, but the unmusical does not survive, nor does the compound of the two, namely, the unmusical man" $\left(190^{\mathrm{a}} 19-21\right) .{ }^{1}$ This compound, the unmusical man, is an example of a kooky object; it goes out of existence when the man becomes musical, and it comes into existence when the man loses his musicality.

On this view, the man and the unmusical man are not identical, since one survives the onset of musicality, while the other does not. Thus, the man, the unmusical man, and the musical man are distinct things. What, then, one wonders, is the relation between the man and the musical man, if it is not identity? Aristotle's answer is that they are accidentally the same $^{2}$ or accidentally one. ${ }^{3}$ That is, they are distinct entities that may, for a time at least, coincide; in the sense they may be, for a time at least, one in number.

Here we have reached our first stumbling block. For it seems decidedly odd to say that two things can be temporarily one. Aristotle's response, I think, would be to say that our ability to distinguish the entities in question does not make them two. For the man-let's call him Coriscus (as Aristotle does at $1015^{\mathrm{b}} 17$ ) - and the musical man are not two men - indeed, they are not two of anything (Matthews 1982, 226). That they are distinct entities (onta) does not, in Aristotle's view, make them two. For "entity" has a variety of senses (as Aristotle puts it, "entity is said in many ways"), ${ }^{4}$ and there is no one sense of "entity" in which both Coriscus and the musical man are both said to be entities. This leads us to a preliminary answer to the question of what kind of things these are that are accidentally the same. Entity, in its primary sense, applies to things in the category of substance, independently existing things such as a man or

\footnotetext{
${ }^{1}$ All translations from Aristotle's works are my own.

${ }^{2}$ Cf. Metaph. $\Delta .9,1017^{\mathrm{b}} 31$ : "Both the man and the musical are said to be the same [in the accidental sense] as the musical man." Cf. also Top. $103^{\mathrm{a}} 30$.

${ }^{3}$ Cf. Metaph. $\Delta .6,1015^{\mathrm{b}} 17$ : "Examples of things that are accidentally one are Coriscus and the musical and musical Coriscus." Clearly, this is not a list of three accidental unities, since Coriscus is one per se and not per accidens. Rather, Coriscus and the musical are accidentally one; Coriscus and musical Coriscus are accidentally one.

${ }^{4}$ Cf. Metaph. Г.2 (esp. $1003^{\mathrm{a}} 33^{-}{ }^{\mathrm{b}}$ ), E.2 (esp. $\left.1026^{\mathrm{a}} 34^{\mathrm{b}}{ }^{\mathrm{b}} 26\right), \mathrm{Z} .1$ (esp. $\left.1028^{\mathrm{a}} 10-30\right)$, K.3 $\left(1060^{\mathrm{b}} 32-1061^{\mathrm{a}} 10\right)$.
} 
a horse. Coriscus is an item in the category of substance, but the musical man with whom he coincides, at least temporarily, is not. ${ }^{5}$

So Coriscus and the musical man with whom he coincides are distinct but are one in number. This way of doing business requires us to be very careful when we are counting, lest we count things that are one in number twice. This may seem a daunting prospect, but we are actually able to handle it pretty well. For example, if we count up the number of U.S. presidents, we get forty-three (George W. Bush is the forty-third president). But if we count up the number of persons who have been president, we get forty-two. This oddity, as everyone knows, is due to Grover Cleveland, who was both the twenty-second and the twentyfourth president. There have been forty-three presidents, but Cleveland was two of them. To put it another way, we've had forty-three presidents, but only forty-two people who have been president. From Aristotle's perspective, it is easy to account for this. When we are counting people who have been president, we are counting persons (substances), but when we are counting presidents, we are counting kooky objects. (This is intended to be an ontological, not a political, comment.) And it turns out that two of those presidents (the twenty-second and the twenty-fourth) coincide with just one person. Of course, they do not coincide with one another. So the relation of coinciding with is not transitive.

The system we actually use to number the presidents makes sense provided that we are comfortable with kooky objects. An ontology that lacks kooky objects, on the other hand, would have to take a different tack here. One such tack would be to claim that we have had, in fact, only forty-two presidents (namely, the forty-two men who have held the office), but then we would get into trouble if we try to retain our current numbering system. For we would have to say that George W. Bush is the forty-third of our forty-two presidents. This does not seem like a happy solution.

So we would be better off to change our numbering system. We could insist that Grover Cleveland was the twenty-second president but not the twenty-fourth - instead, when Cleveland was elected to succeed Benjamin Harrison in 1892, the twenty-second president succeeded the twentythird. And then we would have to say that when Cleveland's second term ended in 1896, the twenty-second president was succeeded by the twentyfourth. On this proposal, the twenty-fourth president turns out not to be Cleveland at all but rather the man who succeeded him-William McKinley - the man who counts, on the numbering system we actually use, as the twenty-fifth president. On this solution, the numbers add up (Bush is the forty-second of our forty-two presidents), but the ordering of presidents becomes strange.

\footnotetext{
${ }^{5}$ Precisely how the musical man fits into Aristotle's categorial scheme is a complicated question, which we will postpone for now.
} 
All this to save the doctrine that the description "the twenty-second president" denotes a substance! By contrast, the Aristotelian treatment of that expression as denoting a kooky object should strike us as eminently sensible. And it is not only sensible, it is the ontology that makes the most sense of our actual practice of counting presidents. ${ }^{6}$

There is a residual problem, of course, concerning identity statements. Because Grover Cleveland was both the twenty-second and the twentyfourth president, we might be inclined to express this by means of these two identity claims.

Grover Cleveland $=$ the twenty-second president

Grover Cleveland $=$ the twenty-fourth president

But then we would be forced by the transitivity of identity to accept:

The twenty-second president $=$ the twenty-fourth president

But this cannot be right, since the former's term of office preceded that of Benjamin Harrison, the twenty-third president, whereas the latter's did not. The twenty-second and twenty-fourth presidents are distinct (kooky) objects. Indeed, they are two different presidents. Grover Cleveland and the twenty-second president, on the other hand, are distinct objects, but they are not two of anything. The first is a substance that coincides with the latter.

Let us end our little foray into American political history and return to Aristotle's example of Coriscus and the musical man. We have determined that they are distinct entities, although they are not two of anything. Since they are not two of anything, one might be tempted (as some of Aristotle's readers have been tempted) to propose that they are, after all, identical, but only contingently so. On this view, the relation of accidental sameness is construed as contingent identity. ${ }^{7}$ Of course, to those who think that identity holds as a matter of necessity where it holds at all, this is a proposal that Aristotle ought to reject. And, in fact, I think he does reject it.

Aristotle would surely admit that it is a contingent fact that Coriscus and the musical man are one and the same. But this is not to say that the contingent fact is that they are identical. Rather, what is contingent is that two nonidentical entities coincide. Although many of the things Aristotle classifies as accidentally the same might be considered contingently identical by proponents of that notion, Aristotle's accidental sameness relation is not contingent identity. ${ }^{8}$ For according to him, things that are accidentally the same are in a way the same, and in a way different. But if

\footnotetext{
${ }^{6}$ Rea 1998 makes a good case for treating many other quite familiar objects (e.g., fists and statues) as kooky.

7 Barnes 1979 makes this suggestion.

8 A convincing case for this has been made in Matthews 1982, 228-29.
} 
$x$ is contingently identical to $y, x$ does not stand to $y$ in some relation weaker than identity. Rather, it is supposed to be a contingent fact that $x$ stands to $y$ in the full-blooded relation of identity. So Aristotle's notion of accidental sameness is not contingent identity. ${ }^{\circ}$

Let us return to the question of what the relation of accidental sameness amounts to. An approach that might sound attractive to contemporary ears is this. Accidental sameness is not some relation weaker than identity. Rather, what Aristotle has discovered is the phenomenon of referential opacity. Coriscus and the musical man are identical, in the strictest sense. However, their names are not interchangeable in all contexts. Sometimes how you refer to something, and not just what you are referring to, affects the truth or falsity of what you say about it. A famous passage in Sophistical Refutations $\left(179^{\mathrm{a}} 33-{ }^{\mathrm{b}} 32\right)$ seems to support this understanding of Aristotle. For there Aristotle describes a case in which you do not know the masked man, but you do know Coriscus, even though the masked man is Coriscus. In this case, we might suppose, whether it is true to say that you know this man depends upon how we describe him. One and the same object is referred to by both the expression "Coriscus" and the expression "the masked man," but it can still be true that you know who Coriscus is but do not know who the masked man is. The reason is that the expression "knows who $x$ is" generates a referentially opaque context.

But this can hardly have been Aristotle's solution to the puzzle of the Masked Man. Aristotle presents the puzzle as an example of the fallacy of accident. According to his official account in the Topics, one commits this fallacy when one claims that something "belongs in the same way both to a thing and also to its accident" (homoiôs ... tôi pragmati kai tôi sumbebêkoti huparkhein, $166^{\mathrm{b}} 29 \mathrm{ff}$.). If one thinks of an accident of $x$ as an attribute that belongs to $x$ accidentally, one may well suppose that Aristotle has in mind the bizarre fallacy of attributing to a thing an attribute of one of its attributes. An example of such a fallacy would be to infer that Socrates is himself a quality from the fact that pallor, one of his attributes, is a quality. Is it possible that this is the kind of fallacy Aristotle has in mind? One might expect Aristotle's examples to clarify the issue, but unfortunately they are not at all helpful.

His two examples are these: (1) Coriscus is different from a man, and Coriscus is a man, therefore, Coriscus is different from himself; (2) Coriscus is different from Socrates, and Socrates is a man, therefore, Coriscus is different from a man. About (2) Aristotle comments tersely that "it is an accident of that from which he has been said to be different

\footnotetext{
${ }^{9}$ A notion of contingent identity like that developed by Stephen Yablo (1987) comes a lot closer to Aristotle's idea. But on Yablo's account, contingently identical things are not, strictly speaking, identical. So contingent identity for Yablo, like accidental sameness for Aristotle, is not a species of identity.
} 
that it is a man" $\left(166^{\mathrm{b}} 36\right)$. But the thing from which Coriscus has been said to be different is Socrates; does Aristotle mean to say that it is an accident of Socrates that he is a man? Although it seems scarcely credible, this does seem to be Aristotle's point. The conclusion of (2) is derived from the first premise by substituting, on the strength of the second premise, the name of the accident ("a man") for the name of what it is an accident of ("Socrates").

So it is difficult to see how these examples either fit the general characterization of the fallacy or correspond to the cases Aristotle subsequently discusses, such as the Masked Man. One might argue that what is accidental in (2) is that it is Socrates, or even that it is a man at all, that has been picked out by the description "thing different from Coriscus." Perhaps that is what Aristotle means when he says that being a man is an accident of the thing that is different from Coriscus. But that still does not explain how "accident" is involved in the substitution of "Coriscus" for "a man" in (1), or "a man" for "Socrates" in (2).

Another possible interpretation, perhaps rather far-fetched, is this: Premise 1 tells us that Socrates is the same, but only accidentally the same, as the thing that is different from Coriscus. So although (premise 2) Socrates is (essentially) a man, it does not follow that the thing that is different from Coriscus is (essentially) a man. For, as Aristotle comments, the conclusion is false (that thing is only accidentally a man). The inference fails because the first premise cites a case of accidental sameness rather than genuine identity. The difficulty here is that the premise "Coriscus is different from Socrates" would have to be both converted and interpreted as a statement of accidental sameness: "Socrates is (accidentally) the same as the thing that is different from Coriscus."

Rather than focus on the examples, we would do better to keep in mind that Aristotle is thinking of a kind of fallacy that would be committed by someone who fails to distinguish entities that are easily confused with one another. And although Socrates is not easily confused with pallor, he is easily confused with something that is pale.

So in Aristotle's account of the fallacy, what he is calling an "accident" is not an attribute but rather something that, as we would say, might or might not have the attribute. When he gives the Masked Man paradox as an example of the fallacy of accident, he identifies Coriscus as the "thing" and the [one] approaching or the masked [one] as the "accident." The fallacy consists in illegitimately transferring an attribute (that of being known) from Coriscus to what he here calls an "accident" of Coriscus, that is, to something accidentally the same as Coriscus, namely, the masked (one).

It is no accident (if I may say so) that Aristotle wants to call such things as the masked [one] accidents. For, as we shall see, such kooky objects play a crucial role in Aristotle's account of accidental predication. The idea, roughly, is that for an attribute to belong accidentally to a subject is 
for that attribute to belong essentially to a different entity, one that coincides with, that is, is one in number with but only accidentally the same as, the subject.

For example, consider Socrates, who is temporarily, and therefore accidentally, seated. Socrates is accidentally the same as the seated one, an entity that, unlike Socrates, is essentially seated. Hence, being seated is an accidental attribute of Socrates.

Once again it is evident that accidental sameness is weaker than identity. For if $x$ and $y$ are accidentally the same, it does not follow that $x$ and $y$ have all the same attributes, that is, that they are indiscernible. Among things that are one in number, it is only things that are "undifferentiated in substance and one in being" (179 37$)$, Aristotle tells us, that are guaranteed to have all the same attributes. Hence, contrary to what Aristotle had said earlier, ${ }^{10}$ sameness simpliciter is not sufficient for indiscernibility. The emended principle looks like this: ${ }^{11}$

Of things that are the same in substance and in being, whatever is predicated of the one may be predicated of the other.

But what exactly does the emendation amount to? Is Aristotle telling us that only some identicals are indiscernible, namely, those that are the same in substance and in being? ${ }^{12}$ Or is he telling us that only some cases of sameness in number are cases of identity? ${ }^{13}$

If Aristotle's point is that only some identicals are indiscernible, his position threatens to be incoherent. For his point at $179^{\mathrm{a}} 37$, on this showing, would be that Coriscus and the masked man, although they are identical, are nevertheless discernible, and hence not the same in substance and in being. But if they are identical, they are one and the same thing. And so on this showing Aristotle must hold that one and the same thing is discernible from itself and not the same as itself in substance and in being. Such a view should not lightly be attributed to Aristotle. ${ }^{14}$

10 At Topics $152^{\mathrm{b}} 25-29$ : "Of things that are the same (tauton), whatever is predicated of the one may be predicated of the other." It would now appear that indiscernibility does not hold for things that are only accidentally the same.

${ }^{11}$ The emended principle also appears at Physics 202 15 : "For not all of the same [predicates] belong to all things whatsoever that are the same, but only to those whose being is the same."

12 See, for example, Hussey $(1983,69)$, who takes Aristotle's point at Physics $202^{\mathrm{b}} 15$ to be that "'Leibniz's Law' need not be true unless there is sameness 'in being' or 'in definition', on top of ordinary identity" (emphasis mine).

13 Another possible interpretation, which I reject, is this: only essentially (i.e., definitionally) equivalent expressions are intersubstitutable salva veritate in all contexts (including modal and epistemic contexts). This is not an account of the strictest kind of sameness relation among entities; it is an account of substitutivity of expressions. But Aristotle is not talking about expressions; he is talking about entities (onta).

14 For a compelling argument that Aristotle does not propose to limit the indiscernibility principle in this way, see Matthews 1982, 233-35. 
Therefore if Aristotle has a coherent point to make here, it must be that sameness in number is a generic notion. One of its species is identity, which, according to Aristotle, holds only between things that are the same in substance and in being; another is accidental sameness, a relation that can hold between things that are not identical. But indiscernibility remains Aristotle's criterion of identity.

What, then, is "sameness in substance and in being"? There seem to be two possibilities. One is that it is sameness at all times. Thus, Socrates is not the same in substance and in being as the seated one because he is not always the same as the seated one; he does not coincide with the seated one at all times. This account will appeal to those who think of a thing's essential attributes as its permanent traits - attributes that it never lacks.

Another possibility has been suggested by Nicholas White, namely, that it is sameness in definition (White 1986, 479-80). What makes this suggestion appealing is that it recognizes that a thing's permanent attributes may not all be essential to it. ${ }^{15}$ Suppose, for example, that Socrates is now pale, has always been pale, and will be pale for as long as he lives. Still, one might argue, Socrates and the pale man with whom he coincides at all actual times and places are nevertheless distinct objects, since they differ in definition. ${ }^{16}$ Being pale is not part of the definition of Socrates, and so he might not have been pale, even if in fact he always is pale. So Socrates is not identical to the pale man he happens to be. According to this criterion of identity, objects are, as White says, individuated modally. And modal individuation obviously yields a fine-grained ontology, such as the one under discussion.

Let us now return to the Masked Man paradox to see how Aristotle's response to it differs from the contemporary appeal to referential opacity. In fact, Aristotle actually considers and rejects a solution that is in some ways similar to the contemporary proposal that psychological verbs generate referentially opaque contexts. According to this solution, it is possible to know and not to know the same thing, but not in the same respect. (Presumably, by "the same thing" here Aristotle means something that he would say is one in substance and in being, and not merely what we would call the same thing but he would say are two things accidentally the same.) $\mathrm{He}$ admits that it is possible to know something in one respect but not another, as one might know that someone is pale but not know that he is musical $\left(179^{\mathrm{b}} 30\right)$. But that is not what is happening in the Masked Man paradox, he claims. For you know that Coriscus is Coriscus, and that the one approaching is the one approaching. So if Coriscus and the one approaching are identical, as the solution he rejects has it, then you know

15 Matthews 1982, 237, makes this point very effectively.

${ }^{16}$ Sameness of definition for concrete particulars in the same species, such as Socrates and Coriscus, is not sufficient for identity, for they are not the same in number. Identity is, properly speaking, sameness in definition and in number. 
that entity - Coriscus, the one approaching - in both respects. That is, you do know, contrary to hypothesis, that the one approaching is Coriscus and that Coriscus is the one approaching. So the solution fails. Hence there must be two entities involved, one of which you know (to be Coriscus), and one of which you do not know (to be Coriscus). Aristotle firmly rejects the idea that Coriscus and the masked man are identical. He thus shows no tendency to believe that the context generated by "knows" is referentially opaque. In effect he insists that it is referentially transparent, but that the two expressions "Coriscus" and "the one approaching" refer to distinct things.

At this point one might be tempted to say that Aristotle's treatment of such cases is similar to Frege's. In explaining why sentences like

Tom believes that Coriscus is Coriscus

Tom believes that the masked man is Coriscus

might differ in truth-value, in spite of the fact that Coriscus is the masked man, Frege famously claimed that in sentences like these, which introduce indirect contexts, the expressions "Coriscus" and "the masked man" do not, despite appearances, have the same denotation (viz., the man Coriscus). Instead, these expression denote distinct entities, viz., the distinct senses that the expressions "Coriscus" and "the masked man" ordinarily have in direct contexts. So Aristotle's move is like Frege's - he insists that expressions that appear to be co-referential actually refer to distinct entities.

But the similarity is only superficial. Although both Aristotle and Frege maintain that expressions that appear to be co-referential are not really so, Aristotle's solution is far more radical than Frege's. For while Frege holds that the reference of an expression may be different from its normal reference when it occurs in certain (indirect) contexts, Aristotle does not suppose that the reference of an expression may vary, depending on the context. On his account, "Coriscus" and "the masked man" do not have (what Frege would call) the same reference in any context. So the "reference shift" that is characteristic of Frege's account is entirely missing from Aristotle's. And the difference is important. For on Frege's account the reference shifts to the sense of an expression-a linguistic item - whereas on Aristotle's account linguistic differences do not enter in at all. The difference is ontological-one expression refers to a substance, the other to a kooky object that coincides with that substance.

How well does Aristotle's solution work? The answer is not altogether clear. One difficulty is that the obviously valid argument "Socrates is Greek, and Socrates is my favorite philosopher, therefore my favorite philosopher is Greek" would count as an instance of the fallacy of accident on Aristotle's account. ${ }^{17}$ Matthews $(1982,238-39)$ grants as

${ }^{17}$ Tony Willing gave this example in discussion when this paper was presented at the conference in Amherst. 
much but proposes to recast the argument in a way that avoids the fallacy: "Socrates is Greek, and Socrates has the attribute of being my favorite philosopher, therefore someone who has the attribute of being my favorite philosopher is Greek." To derive the conclusion of this argument, as Matthews points out, requires only the principles of conjunction and existential generalization, and does not require substitutivity.

I am inclined to take a slightly different tack. On Aristotle's account, for my favorite philosopher to be Greek is for a certain kooky object ( $m y$ favorite philosopher) to be accidentally the same as a substance that has the attribute of being Greek (cf. Metaph. $\Delta .9,1017 \mathrm{~b} 28$ : "The white and the musical are the same because they are accidents of the same thing"). In other words, for my favorite philosopher to be Greek is really for the substance that underlies my favorite philosopher to be Greek. On the other hand, for Socrates to be my favorite philosopher is for him to be (i.e., to be identical to) the substance that underlies that kooky object. The argument, properly construed, then, looks like this: "Socrates is Greek, and Socrates is (identical to the substance underlying) my favorite philosopher, therefore (the substance underlying) my favorite philosopher is Greek." Since the second premise is a claim of identity (not accidental sameness), the principle of substitutivity applies, and the argument does not commit the fallacy of accident after all.

Notice that a similar salvage effort will not rescue the truly fallacious argument in the paradox of the Masked Man. For although Coriscus is identical to the substance underlying the masked man, and you know who Coriscus is, it does not follow that you know who the masked man is. All that follows is that you know who the substance underlying the masked man is, that is, that you know who Coriscus is. You know of the substance underlying the masked man, that is, of Coriscus, that he is Coriscus, but you do not know of the masked man that he is Coriscus.

Still, not all substitutivity puzzles are amenable to the treatment Aristotle proposes. Cicero and Tully, for example, are identical, not merely accidentally the same. So Aristotle's solution to the Masked Man paradox will not help us to understand how one can believe that Cicero, but not Tully, denounced Cataline (see Matthews 1982, 238).

Nor is this shortcoming limited to cases in which the intersubstituted expressions are proper names; Cicero and Tully are just a special case of things that are the same in definition. Thus, Coriscus may be the same in definition as this man, and yet it would seem possible to know that Coriscus is approaching without knowing that this man is approaching, if one does not know that Coriscus is a man. The problem arises because it seems to be possible to recognize something (in some sense) without knowing (strictly speaking) what it is. Indeed, Aristotle's idea that essence is discovered seems to commit him to this possibility.

On the other hand, there are passages where Aristotle expresses the contrary idea that such cases are not possible, and that "there are no 
mistakes about essence." 18 It is likely, however, that he would try to assimilate such cases to ones involving kooky objects. In De anima III.6 $\left(431^{\mathrm{b}} 27\right)$, after pointing out that "thinking of the definition in the sense of what it is for something to be is never in error," Aristotle concedes that "seeing whether the white object is a man or not may be mistaken."

It might appear that this would enable Aristotle to extend the kooky object solution to a related puzzle case in which you know that Coriscus is approaching but do not know that Coriscus the man is approaching. But that is not so clear.

Suppose that I don't know that Coriscus is a man but still, in some sense, know that Coriscus is approaching. I must have some way of picking out the thing I take to be approaching. If I pick it out as the pale thing, then it isn't really Coriscus that I know to be approaching, but rather the pale thing. If I succeed in really picking out Coriscus, rather than something accidentally the same as Coriscus, I will have to pick him out as a man. So I will, after all, know that Coriscus the man is approaching if I know that Coriscus is approaching. It thus appears that in at least some cases, the kooky object solution to substitutivity puzzles will not work.

\section{II}

So far we have found kooky objects in only a few of Aristotle's texts, where they play a role in solving puzzles about change and about substitutivity in indirect contexts. It was natural for us to begin with these texts, for they are the ones that all of us "kookologists" appeal to. I want to turn now to some other texts where, I will claim, kooky objects also have an important, although less frequently recognized, role to play.

It will be useful, before we begin, to distinguish between what I'll call simple kooky objects (such as the pale [one]) and compound kooky objects (such as the pale man). The distinction is in fact a vexed one, since not all kookologists agree that kooky objects come in these two flavors. On Frank Lewis's account of the matter, all kooky objects are what he calls accidental compounds (Lewis 1982, 5). That is to say, the expressions "the generous [one]" and "generous Socrates" may, in a given context, have the same denotation. The expression "the generous [one]" may be simple, but the entity it denotes - the kooky object - is always a compound of an accident and an underlying "parent" 19 substance. For White, on the other hand, the two expressions do not have the same denotation (White 1986, $492 \mathrm{n}$. 6). In his view, the generous [one] is a component of the compound generous Socrates, but is itself neither a compound nor an attribute. I

${ }^{18}$ Cf. Metaph. $1051^{\mathrm{b}} 25,1027^{\mathrm{b}} 26$; De An. $431^{\mathrm{b}} 27$; and White 1986, 482.

19 I follow Lewis 1982 , 1, in so describing the substance with which a kooky object coincides. 
should point out that Gary is a neutral observer in this dispute. He does not take a stand on the question whether the unmusical and the unmusical man are the same kooky object (Matthews 1982, 225).

My view is closer to White's than to Lewis's here. I think Aristotle would want to distinguish simple kooky objects, such as the pale, from compound kooky objects, such as the pale man; for the first is essentially pale but not essentially human, while the second is both essentially pale and essentially human. The pale and the pale man may coincide, of course, and hence be one in number - indeed, they are one and the same man - but they are not identical. They cannot be identical, since they have different essential properties. I will not argue in favor of this approach, but I hope the reasons for my preference become apparent as we proceed.

I begin with the Categories. It is a commonplace that in that work Aristotle divides the entities in his ontology into ten fundamental classes: substances, qualities, quantities, relatives, and so on. Substances are independently existing entities; nonsubstances, the items in the other nine categories, are dependent entities. When one considers only substances and qualities, all seems clear enough. This horse is a substance, an independently existing entity. The whiteness in the horse is a quality, a dependent entity. ${ }^{20}$

When one looks into the other categories, however, the picture becomes cloudy. The category of relatives includes such items as a master, a slave, the wing of a bird, the rudder of a boat, a head, and a hand. Presumably fathers and daughters also go into this category. But these do not seem to be dependent entities in the same way that qualities are. Indeed, it seems as if these items are all substances, or at least parts of substances, and not ontologically dependent entities. One might say, of course, that one and the same entity may be a substance under one description ("man") and a relative under a different description ("father" or "slave"). That is, one may hold that the contexts "is a relative" and "is a substance" are referentially opaque. But that does not solve our problem. For it does not explain why relatives are dependent entities, which cannot exist apart from the substances that they are (in some sense) in. Perhaps one might say that this claim about relatives is also referentially opaque. But if nothing can be said about the items in Aristotle's fundamental ontological scheme without inducing referential opacity, the notion of reference itself seems to lose its foothold. There must be at least some transparent contexts.

By contrast, the theory of kooky objects handles relatives with aplomb. That man and that father are distinct, but coincidental, objects. One is

${ }^{20}$ I will ignore the longstanding and contentious dispute about precisely what this dependent entity is (a nonshareable and nonrepeatable trope? a fully determinate universal?), and on what it depends (the particular substance it is in? the kind of substance it is in? its being in some substance or other?). 
a substance, the other a relative. The substance can exist without the relative that depends on it, but not conversely. That father cannot exist if the man that he inheres in does not exist. Notice that the items in this category are not relations, like fatherhood or being larger than; rather, they are (among) the things that instantiate these relations - things that are fathers, or that are larger than something. By the same token, we should say that the items in the category of poion (literally, "like what" although usually, and misleadingly, translated as "quality") are not qualities but things qualified. What is ontologically dependent on Coriscus is not pallor but the pale, that is, the pale thing with which Coriscus coincides. ${ }^{21}$

Consider another accidental category, that of place. How is it, one might wonder, that a place is incapable of existing apart from the substance that is located at it? Coriscus is in the Lyceum, and he can exist apart from the Lyceum. But surely the Lyceum can exist apart from Coriscus, indeed, apart from there being any substances at all located there. But note that Aristotle lists in the Lyceum (rather than the Lyceum itself) as an example of an item in this category. This suggests that the category is not that of place but that of things placed. (Aristotle actually calls it the category of where.) So an example of something in this category might be the one in the Lyceum. This, of course, is something whose location is its essence, but which happens to coincide with Coriscus for as long as the latter is in the Lyceum, and whose existence depends on that of Coriscus. Once again, an individual in a nonsubstance category turns out to be a kooky object.

The hypothesis that the individuals in most of the nonsubstance categories are (simple) kooky objects thus explains a number of otherwise peculiar and perhaps uninterpretable claims that Aristotle makes in the Categories. It must be conceded, however, that this hypothesis does not work so well for the individuals of the category of quality. Aristotle tells us that such entities as "the brave" and "the pale" get their names from bravery and pallor, and are therefore paronyms $\left(1^{\mathrm{a}} 12-15,10^{\mathrm{a}} 30\right)$. And we should not expect a paronym to belong to the same category as the thing it is a paronym of. For example, at $6^{\mathrm{b}} 11$ we are told that to-be-sitting, an item in the category of being-in-a-position, is a paronym of sitting, which is a position, an item that Aristotle puts in the category of relatives. On my hypothesis, these paronyms in the category of being-in-a-position are kooky objects - things positioned. So a kooky object like the seated one would be a paronym of something in a different category-that of relatives. Similarly, Aristotle's idea would seem to be that the paronyms of a given quality are not themselves entities in the category of quality.

21 I suspect that Aristotle was not completely clear on this at the time he wrote the Categories. So I need not disagree with White (1986), who holds that the kooky objects of the Physics and later works enter Aristotle's ontology as a replacement for the individual non-substances of the Categories. 
So at least in the case of qualities and positions, it seems unlikely that in the Categories Aristotle thought of kooky objects ("the pale," "the seated one") as an alternative to more property-like entities (pallor, sitting). I suspect that at the time of the Categories Aristotle did not have a coherently worked out position about these ontological issues. (Cf. Lewis 1982, 2-4; White 1986, 494 n. 32.)

\section{III}

I will conclude with a brief look at the place of kooky objects in the Metaphysics. The first thing to note is that here, the ontological priority just noted of qualities over things qualified begins to reverse itself. Whereas in the Categories an item like the brave seems to depend upon the quality (e.g., bravery) it is named after, Metaphysics Z.1, $1028^{\mathrm{a}} 20$, suggests the opposite. The walker (to badizon) and the sitter (to kathêmenon) and the healthy one (to hugiainon), we are told, have a better claim to be called beings than do walking (to badizein) or sitting (to kathêsthai) or being healthy (to hugiainein), presumably because they are more substantial than the qualities and positions they supplant. Notice that Aristotle's point is not just that substances are ontologically prior to qualities and positions. Of course, substances are ontologically prior to qualities, but that is not his point here. The entities that Aristotle here claims to be ontologically prior (literally, "more real," mallon onta) are the walker, the sitter, and the healthy one, and these are not substances. What makes them more real, says Aristotle, is that "there is something definite which underlies them; and this is the individual substance" (1028a26-7). So there are three different entities mentioned here, which should be listed in the following order of priority - (1) the underlying substance, (2) the kooky object that coincides with the substance, and (3) the quality or position that the substance has by virtue of coinciding with the kooky object.

A kooky object is clearly not a substance, something that exists in its own right; rather, it depends for its existence on the substance with which it coincides. A compound kooky object, like the musical man, is doubly dependent; it depends for its existence not only on its underlying substance but also on the simple kooky object, the musical. Simple kooky objects are also dependent entities; the musical exists only because it coincides with some substance or other.

But what more can be said about the substances on which these objects depend? It is tempting to think that they are simply the primary substances of the Categories ("c-substances"), ${ }^{22}$ but that would not be correct. For from the hylomorphic perspective of the Metaphysics, csubstances are composites of matter and form and are therefore

${ }^{22}$ I adopt the terminology of Wedin 2000. 
substances in only a secondary sense. It is forms, not composites, that are the primary substances of the Metaphysics. A c-substance is a highly complex entity, with many nonrelational properties, both essential and accidental. Its essential properties are those that are part of the definition of its form; its accidental properties are those that are essential to the various kooky objects with which it coincides. That is, what makes a c-substance essentially two-footed is that being two-footed is part of what it is, not something that holds of it merely by way of coincidence. What makes a c-substance accidentally musical is that its underlying primary substance coincides with a kooky object that is essentially musical.

On this account, a primary substance's accidental properties are all relational. For a primary substance has its various accidental properties in a derivative way, by coinciding with various kooky objects. Considered apart from the kooky objects with which it coincides, a primary substance's only properties are essential and nonrelational. This is what distinguishes a primary substance of the Metaphysics from the c-substances of the Categories. It is a primary substance, not a compound, that stands in the relation of coincidence to kooky objects. Such a substance is not a composite of matter and form but a form in virtue of which a composite is the kind of thing that it is. A primary substance does not have the nonrelational accidental properties that c-substances have. To arrive at a primary substance we must peel the accidental properties away from a c-substance. That is to say, we must separate from the c-substance the kooky objects with which its parent substance coincides.

When we have done this, we will notice a somewhat surprising result-primary substances are in one respect a lot like simple kooky objects. Neither of them has any accidental properties apart from their coinciding with other things. The man who coincides with the pale and with the musical, and so forth, is in his own right neither pale nor dark, neither musical nor unmusical. He is, of course, two-footed and rational, assuming that these features are part of his definition. But the substance itself, like the kooky objects with which it coincides, has no nonrelational accidental properties. A primary substance is what we are left with after we have abstracted away from a composite substance all of its accidents.

Kooky objects thus fit perfectly into the substance ontology of Aristotle's Metaphysics. A traditional puzzle concerning the primary substances of the Metaphysics is how they are related, on the one hand, to the "ordinary" particulars of (what one might call) folk ontology and, on the other hand, to the abstract properties, or essences, which make those ordinary particulars the kinds of things that they are. It seems clear enough that primary substances cannot be identified with either the particulars of folk ontology or their abstract essences. ${ }^{23}$ Primary sub-

23 It is tempting to argue, as Wedin 2000 in effect does, that Aristotle uses the word "substance" in two different senses, one for c-substances and the other for the substances 
stances are definable, whereas ordinary particulars (c-substances, his composites of matter and form) are, by his lights, not definable. Primary substances are also "thises," that is, subjects of predication rather than entities inherently predicated of something else, as abstract essences seem to be.

Neither a composite individual, such as Socrates, nor a universal, such as the property of being human, seems to qualify as an Aristotelian primary substance. What kind of entity, then, is a primary substance? Is it some other kind of individual or some other kind of universal? On this particularly vexed question of Aristotelian scholarship, the present interpretation is silent - a feature that may actually be an argument in its favor. Since a substance can be one in number with a particular kooky object, it might appear to be an individual itself. Yet the only nonrelational properties a substance has are those essential properties that define it. So the man who coincides with the pale one and the man who coincides with the dark one are the same in being, and indiscernible. This makes the primary substance, the man, appear to be more like a universal: one thing capable of coinciding, simultaneously, with many different things. It is not surprising, then, that Aristotelian substances should be construed as individuals by some interpreters and as universals by others.

Here is another way to put the point. It is obvious that an ontology that restricts itself to ordinary individuals (i.e., c-substances, later identified as hylomorphic compounds) and their abstract properties will have to reject kooky objects. But such an ontology will also, and for the same reasons, have to reject the primary substances of the Metaphysics. If we want to construct an Aristotelian ontology, we will want to make room for those substances. In so doing, I have been arguing, we will also be making room for kooky objects. ${ }^{24}$

\author{
Department of Philosophy \\ Box 353350 \\ University of Washington \\ Seattle, WA 98195 \\ USA \\ smcohen@u.washington.edu
}

(i.e., essences) of those c-substances. In that case, Aristotle will face a difficult question: Which of these substances is primary? Or are they both primary, but in different ways? On the present interpretation, these questions do not arise.

${ }^{24}$ Thanks are due to Tom Blackson, my commentator when this paper was presented at Amherst, and to several members of the audience there, especially Tony Willing and Calvin Normore, for their comments and questions. I especially want to express my gratitude to Gary Matthews for inspiring me to write on this topic, and for his endless support and encouragement over the past forty years. 


\section{References}

Barnes, Jonathan. 1979. Review of Hartman, Substance, Body, and Soul. Philosophical Books 20:59.

Barnes, Kenneth T. 1972. "Aristotle on Identity and Its Problems." Phronesis 22:48-62.

Code, Alan 1976. "Aristotle's Response to Quine's Objections to Modal Logic." Journal of Philosophical Logic 5:159-86.

Cohen, S. Marc 1978. "Essentialism in Aristotle." Review of Metaphysics 31:387-405.

Hartman, Edwin. 1976. Substance, Body, and Soul: Aristotelian Investigations. Princeton: Princeton University Press.

Hussey, Edward. 1983. Aristotle's Physics III and IV. Oxford: Oxford University Press.

Lewis, Frank. 1982. "Accidental Sameness in Aristotle." Philosophical Studies 42:1-36.

Matthews, Gareth B. 1982. "Accidental Unities." In Language and Logos, edited by Malcolm Schofield and Martha Nussbaum, 223-40. Cambridge: Cambridge University Press.

_ 1990. "Aristotelian Essentialism." Philosophy and Phenomenological Research 50, supp.:251-62.

- 1992. "On Knowing How to Take Aristotle's Kooky Objects Seriously." Paper presented at the Pacific Division meeting of the APA, Portland, March 27, 1992.

Pelletier, F. J. 1979. "Sameness and Referential Opacity in Aristotle." Noûs 13:283-311.

Rea, Michael C. 1998. "Sameness without Identity: An Aristotelian Solution to the Problem of Material Constitution." Ratio 11:316-28.

Smith, Robin. 1989. Aristotle: Prior Analytics. Indianapolis: Hackett.

Spellman, Lynne. 1989. "Specimens of Natural Kinds and the Apparent Inconsistency of Metaphysics Zeta." Ancient Philosophy 9:49-65.

—. 1990. "Referential Opacity in Aristotle." History of Philosophy Quarterly 7:17-32.

Wedin, Michael. 2000. Aristotle's Theory of Substance. Oxford: Oxford University Press.

White, Nicholas. 1971. "Aristotle on Sameness and Oneness." Philosophical Review 80:177-97.

- 1986. "Identity, Modal Individuation, and Matter in Aristotle." Midwest Studies in Philosophy 11:475-94.

Williams, C. J. F. 1985. "Aristotle's Theory of Descriptions." Philosophical Review 94:63-80.

Yablo, Stephen. 1987. "Identity, Essence, and Indiscernibility." Journal of Philosophy 84:293-314. 